\title{
RESEARCH
}

Open Access

\section{Alterations of peripheral nerve excitability in an experimental autoimmune encephalomyelitis mouse model for multiple sclerosis}

Nathalia Bernardes Teixeira ${ }^{1,2,3}$, Gisele Picolo², Aline Carolina Giardini², Fawzi Boumezbeur ${ }^{3}$, Géraldine Pottier ${ }^{4}$, Bertrand Kuhnast ${ }^{4}$, Denis Servent ${ }^{1}$ and Evelyne Benoit ${ }^{1 *}$ (D)

\begin{abstract}
Background: Experimental autoimmune encephalomyelitis (EAE) is the most commonly used and clinically relevant murine model for human multiple sclerosis (MS), a demyelinating autoimmune disease characterized by mononuclear cell infiltration into the central nervous system (CNS). The aim of the present study was to appraise the alterations, poorly documented in the literature, which may occur at the peripheral nervous system (PNS) level.

Methods: To this purpose, a multiple evaluation of peripheral nerve excitability was undertaken, by means of a minimally invasive electrophysiological method, in EAE mice immunized with the myelin oligodendrocyte glycoprotein (MOG) 35-55 peptide, an experimental model for MS that reproduces, in animals, the anatomical and behavioral alterations observed in humans with MS, including CNS inflammation, demyelination of neurons, and motor abnormalities. Additionally, the myelin sheath thickness of mouse sciatic nerves was evaluated using transmission electronic microscopy.

(Continued on next page)
\end{abstract}

\footnotetext{
* Correspondence: evelyne.benoit@cea.fr

'Université Paris-Saclay, CEA, Département Médicaments et Technologies pour la Santé (DMTS), Service d'Ingénierie Moléculaire pour la Santé (SIMoS), ERL CNRS 9004, Gif-sur-Yvette, France

Full list of author information is available at the end of the article
}

(c) The Author(s). 2020 Open Access This article is licensed under a Creative Commons Attribution 4.0 International License, which permits use, sharing, adaptation, distribution and reproduction in any medium or format, as long as you give appropriate credit to the original author(s) and the source, provide a link to the Creative Commons licence, and indicate if changes were made. The images or other third party material in this article are included in the article's Creative Commons licence, unless indicated otherwise in a credit line to the material. If material is not included in the article's Creative Commons licence and your intended use is not permitted by statutory regulation or exceeds the permitted use, you will need to obtain permission directly from the copyright holder. To view a copy of this licence, visit http://creativecommons.org/licenses/by/4.0/. The Creative Commons Public Domain Dedication waiver (http://creativecommons.org/publicdomain/zero/1.0/) applies to the data made available in this article, unless otherwise stated in a credit line to the data. 
(Continued from previous page)

Results: As expected, the mean clinical score of mice, daily determined to describe the symptoms associated to the EAE progression, increased within about 18 days after immunization for EAE mice while it remained null for all control animals. The multiple evaluation of peripheral nerve excitability, performed in vivo 2 and 4 weeks after immunization, reveals that the main modifications of EAE mice, compared to control animals, are a decrease of the maximal compound action potential (CAP) amplitude and of the stimulation intensity necessary to generate a CAP with a 50\% maximum amplitude. In addition, and in contrast to control mice, at least 2 CAPs were recorded following a single stimulation in EAE animals, reflecting various populations of sensory and motor nerve fibers having different CAP conduction speeds, as expected if a demyelinating process occurred in the PNS of these animals. In contrast, single CAPs were always recorded from the sensory and motor nerve fibers of control mice having more homogeneous CAP conduction speeds. Finally, the myelin sheath thickness of sciatic nerves of EAE mice was decreased 4 weeks after immunization when compared to control animals.

Conclusions: In conclusion, the loss of immunological self-tolerance to MOG in EAE mice or in MS patients may not be only attributed to the restricted expression of this antigen in the immunologically privileged environment of the CNS but also of the PNS.

Keywords: Electrophysiology, Experimental autoimmune encephalomyelitis, Mouse, Multiple sclerosis, Myelin oligodendrocyte glycoprotein, Neuromuscular junction, Peripheral nervous system

\section{Introduction}

Multiple sclerosis (MS) is a chronic, inflammatory, and demyelinating disorder of the central nervous system (CNS), considered as an important and frequent neurological impairment condition [1, 2]. It is a disorder of autoimmune origin, where the immune system recognizes parts of the CNS as antigens, specifically peptides that form the myelin sheath of axons of neurons [3-5] leading to a demyelination process which induces serious physical, cognitive, emotional, and social problems $[1,2]$. Although the evolution of the disease is highly variable, the disability faced by most people is irreversible. Therefore, MS is considered incurable, and the different therapeutic options focus on delaying disease progression and promoting the relief of symptoms so as to maintain the quality of life of patients [2]. In contrast to therapies focused on controlling or modulating the immune (innate and adaptive) responses to limit demyelination and neuronal damage, novel drugs currently in clinical trial have been recently reported to promote repair and regeneration in the CNS [6].

The immunopathogenesis of MS is not completely understood, and it sets up as a picture that remains to be elucidated. However, important steps are clearly involved in this disease, primarily at the CNS. Both innate and adaptive immune system responses are dysregulated in MS [7]. It is a mainly $\mathrm{T}$ cell-mediated disease with a central role of myelinreactive $\mathrm{CD}^{+} \mathrm{T}$ cells $[8,9]$. Autoreactive T-helper type 1 (Th1) and 17 (Th17) cells are peripherally activated and subsequently migrate to the CNS, causing central inflammation with release of cytokines, microglial activation, axonal and myelin injury, followed by demyelination and atrophy of white matter tract across the brain and spinal cord [10-12], which causes neurological and motor impairment. The atrophy occurs in key regions. Posterior cingulate cortex, precuneus, and thalamus are among the earliest regions to become atrophic [13]. In addition to the neuroinflammation, some other factors may underlie the neurodegeneration and brain atrophy, including mitochondrial failure, iron deposition, and retrograde neurodegeneration in the deep gray matter through white matter lesions [14-16].

B cells and antibodies have also a role in the pathology of MS. High levels of immunoglobulins in the cerebrospinal fluid of patients were detected together with an increase in these levels during periods where the symptoms were worse [17-19]. The production of myelinspecific antibodies (and the consequent rupture of myelin sheets) seems to be an important way in which B cells contribute to the disease [19]. Recently, a more central role of B cells in MS, which appears to be antibody independent, has been described [20, 21]. According to this recent scenario, B cells would activate or downregulate the proinflammatory responses of both myeloid and $\mathrm{T}$ cells, and recruit autoreactive $\mathrm{T}$ cells to the CNS. Thereafter, interactions among these cells would determine the development of MS episodes.

In contrast to the well-defined and critical central effect, the peripheral alterations, although frequently described in patients, have not been characterized as thoroughly [22-25]. In particular, histological studies performed on rats with experimental autoimmune encephalomyelitis (EAE) showed that inflammation was present in both peripheral nervous system (PNS) and CNS [22]. In this model of EAE induced by passive transfer of a cytotoxic $\mathrm{CD} 4^{+} \mathrm{T}$ cell clone specific for the 72-89 peptide of guinea-pig myelin basic protein (MBP), 
the spinal roots in the PNS as well as the spinal cord root entry and exit zones in the CNS were considered as the main sites of demyelination at periphery. More recently, electrophysiological analysis revealed a membrane hyperexcitability of sensory neurons of dorsal root ganglia isolated from $\mathrm{MOG}_{35-55}$-induced EAE mice, providing evidence of peripheral sensitization in MOG-EAE murine model [23].

The frequency of peripheral demyelination in a whole MS population is unknown, although some case reports have been described to be associated with demyelinating neuropathy [26, 27].

Few studies have investigated peripheral alterations induced by MS. Hence, peripheral sensory and motor abnormalities were analyzed in 20 patients showing MS by evaluating conduction velocities and amplitudes of ulnar, sural, and tibial nerves. Electrophysiological abnormalities were found in 15 of 91 nerves examined (16.5\%) but neurological disability was not associated with the presence of electrophysiological abnormalities [28]. In addition, nerve conduction abnormalities suggestive of demyelination were demonstrated in only $5 \%$ of 60 patients with relapsing-remitting MS [29]. This later study, in contrast to a number of case reports describing patients with MS who develop demyelinating neuropathy, strongly suggests that central and peripheral demyelination coexist only in a special subgroup of patients with MS.

The aim of the present work was to study the peripheral impairment induced by MS. To this purpose, peripheral sensory and motor nerve excitability was evaluated in a $\mathrm{MOG}_{35-55}$-induced EAE mouse, an experimental model for MS that reproduces, in animals, the anatomical and behavioral alterations observed in humans with MS, including CNS inflammation, demyelination of neurons, and motor abnormalities [3, 30-32].

\section{Materials and methods Animals}

Animal experiments are reported in line with the ARRIVE (Animal Research: Reporting of In Vivo Experiments) guidelines developed in consultation with the scientific community as part of an NC3Rs initiative to improve standards of reporting the results of animal experiments, maximizing information published, and minimizing unnecessary studies [33, 34]. Experiments were carried out on 8-week-old female C57BL/6 mice (Mus musculus, weighting 18-20 g) purchased from Janvier Elevage (Le Genest-Saint-Isle, France). We used exclusively female mice taking into account that first, MS is an autoimmune disease where the incidence is higher in women than in men [35-37] and second, most of the previous studies were performed on female animals. The animals were acclimatized at the CEA animal facility for at least $48 \mathrm{~h}$ before experiments, and were treated in strict adherence with the European Community guidelines for laboratory animal handling and to the guidelines established by the French Council on animal care "Guide for the Care and Use of Laboratory Animals" (EEC86/609 Council Directive-Decree 2001-131). In particular, the mice were housed in a room with controlled temperature and a 12-h light/12-h darkness cycle, in standard laboratory cages with environmental enrichment (bedding and cardboard tubes), and were allowed to free access to water and food.

All animal experimental procedures were approved by the Animal Ethics Committee of the CEA, by the French General Directorate for Research and Innovation (project APAFIS\#5973-2016070515456532v6 authorized to FB and project APAFIS\#2671-2015110915123958v4 authorized to EB) and by the Butantan Institute (CEUAIB protocol number 7334170718 authorized to GP).

\section{EAE mouse model}

EAE was induced as previously described [38, 39]. Briefly, each EAE mouse was immunized with $200 \mu \mathrm{g}$ of synthetic myelin oligodendrocyte glycoprotein (MOG) 35-55 peptide (MEVGWYRSPFSRVVHLYRNGK) with purity greater than $95 \%$. The peptide was emulsified in incomplete Freund's adjuvant (IFA; InvivoGen, France) supplemented with $400 \mathrm{mg} / \mathrm{mL}$ of Mycobacterium tuberculosis to lead to complete Freund's adjuvant (CFA), and injected subcutaneously near the base of the tail in a $200-\mu \mathrm{L}$ volume. Immediately after immunization and 2 days later, mice were intraperitoneally injected with 300 $\mathrm{ng} / \mathrm{kg}$ of pertussis toxin from Bordetella pertussis bacteria (PTX; Sigma-Aldrich, Saint-Quentin Fallavier, France) in a $200-\mu \mathrm{L}$ volume. The control animals (CFAmice) were similarly injected with CFA free of $\mathrm{MOG}_{35-55}$ peptide and pertussis toxin.

Six mice (MOG-M1 to MOG-M6) were immunized at day 0 . Recordings were performed at days 14 and 28, i.e., 2 and 4 weeks after immunization, and compared to those of six age-matched control animals (CFA-M1 to CFA-M6). All mice were daily observed for clinical signs. The references used to assess the clinical scores of EAE mice, assigned by an observer who was blinded to the treatment, were the flaccidity or paralysis of the tail (first sign), and the drag of the hip without limb paralysis (second sign) or associated with hind-limb (third sign) and then fore-limb (forth sign) paralysis.

\section{In vivo electrophysiology}

Recordings were performed by means of a minimally invasive electrophysiological method. The principle is to electrically stimulate a nerve trunk and to record, in return, the compound action potential (CAP) resulting from the activity of all fibers composing the stimulated 
nerve ("sensory nerve recordings") or muscle ("motor nerve recordings").

After being weighed, each mouse was placed in an anesthesia-induction chamber in which a mixture of oxygen (0.4 L/min via an oxygen extractor), air $(0.2 \mathrm{~L} / \mathrm{min}$ via an air condenser), and isoflurane (AErrane ${ }^{\circ}$, Baxter S.A., Lessines, Belgium; $2.0-2.5 \%$ via an anesthetic diffuser) was diffused. When the mouse was asleep, it was taken out of the chamber and set on a plate heated using water circulation (via a $\mathrm{T} /$ PUMP). Its muzzle was positioned at the level of a mask which continuously delivered the anesthetic gas mixture to keep the animal asleep, and its two hind-limbs were fixed by adhesive tape (Fig. 1). If necessary, the percentage of isoflurane was adjusted to maintain the anesthesia. The animal temperature was measured using a digital thermometer equipped with a rectal probe.

The electrical stimulations were delivered to either the caudal or sciatic nerve by two stimulators (A395, World Precision Instruments, Sarasota, FL, USA) via two nonpolarizable $\mathrm{Ag} / \mathrm{AgCl}$ external electrodes, the anode ( $\mathrm{RC} 4$, World Precision Instruments) and the cathode (RC3, World Precision Instruments), directly affixed to the skin of the mouse. A medical gel (Polaris II) was used to improve the contact, i.e., the electrical conduction, between the electrodes and the skin. For sensory nerve recordings, the electrodes were located at the distal portion of the mouse tail, the anode being in the most distal position and the cathode about $1 \mathrm{~cm}$ from the anode. For motor nerve recordings, the anode was placed at the level of the ankle of the right or left hind-limb studied, and the cathode at the base of the tail (Fig. 1).

The CAP [compound nerve action potential (CNAP) and compound muscle action potential (CMAP) for sensory and motor nerve recordings, respectively], which propagated in the stimulated nerve, was collected by means of two detection electrodes E1 and E2 (MF3.OE.1F35.12, Comepa) which were very fine needles inserted (i) in the proximal part of the tail, the electrode E2 being in the most proximal position and the electrode E1 about $1 \mathrm{~cm}$ from the electrode E2 (sensory nerve recordings); (ii) in the distal part of the tail, the electrode E2 being in the most distal position and the electrode E1 about $1 \mathrm{~cm}$ from the electrode E2 (motor nerve recordings from the tail muscle); and (iii) in the right or left hind-limb (motor nerve recordings from the plantar muscle). These electrodes were connected to an amplifier (Disa EMG 14C13, Sklovlunde) to increase the

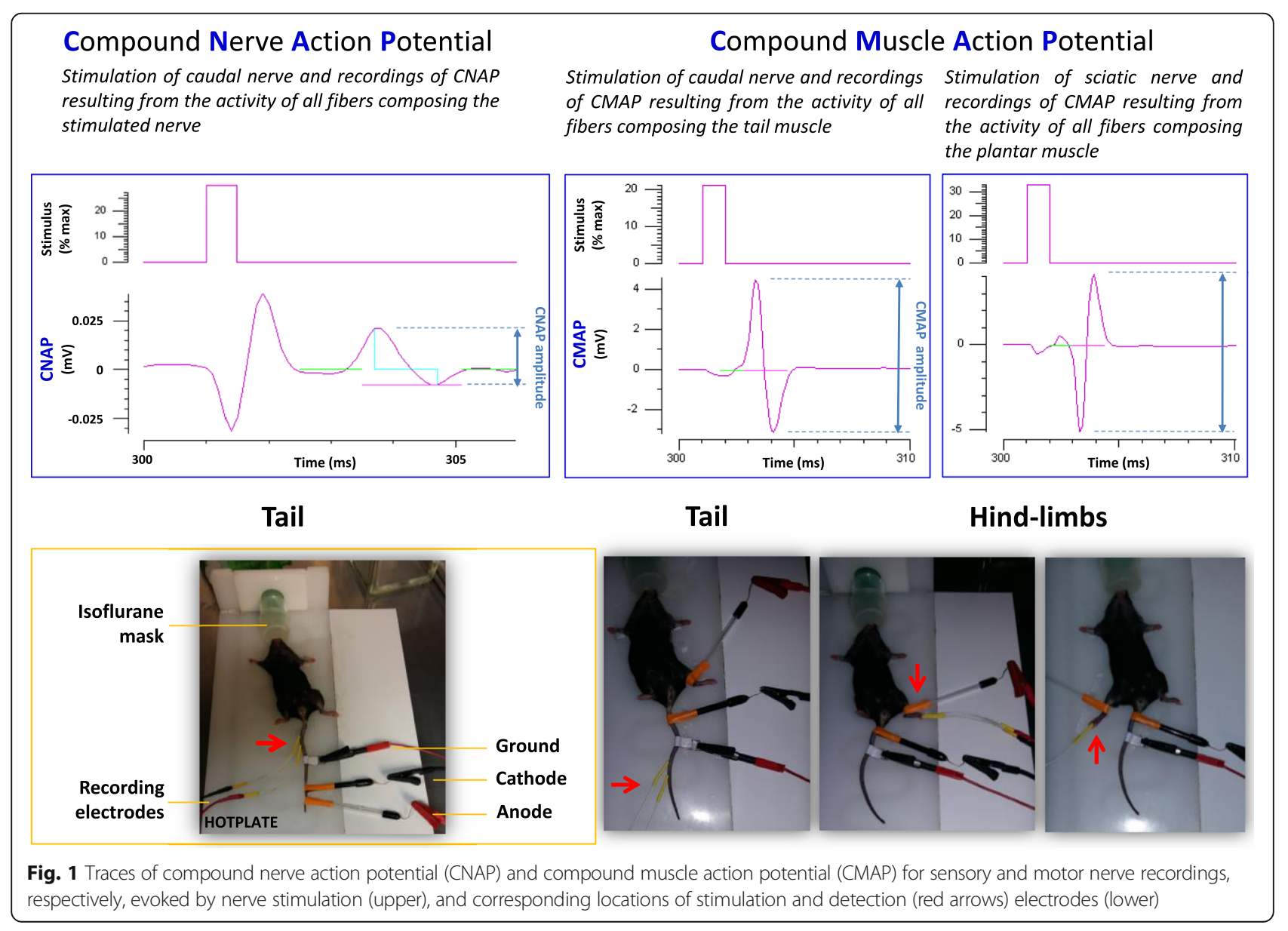


CAP amplitude, and then to a "hum bug" (Quest Scientific) to eliminate the sinusoidal noises that are inherent to electrophysiological recordings. Finally, a ground electrode was placed between the cathode and the detection electrodes for sensory and motor nerve recordings from the tail, or below the cathode for motor nerve recordings from the right or left hind-limb (Fig. 1).

The multiple evaluation of sensory and motor nerve excitability properties was performed using the Qtrac(c) software $(\mathrm{H}$. Bostock, Institute of Neurology, London, U.K.). By means of a digital-to-analog converter (DAQ2000, Iotech), this software allowed the delivery of the stimulation sequences and, in return, managed the recordings (at a sampling frequency of $10 \mathrm{kHz}$ ) and analysis of the CNAP and CMAP collected from the stimulated nerve and muscle, respectively (Fig. 1). It should be emphasized that, under these conditions, the CAP in response to a single stimulation was biphasic, i.e., a positive phase followed by a negative one or a negative phase followed by a positive one, according to the relative positions of the two electrodes, since it represented the potential difference between the two detection electrodes, i.e., E1-E2. Its amplitude was measured as the absolute difference between the maxima of these two phases (Fig. 1).

\section{Protocols, data analyses, and statistics}

The stimulation protocol ("QTracS" program) lasted a few minutes and consisted in establishing the stimulusresponse curve, i.e., the relationship between the CAP amplitude and the stimulation intensity, as exemplified for the CNAP in Fig. 2. Firstly, the CAP amplitude was measured as a function of the intensity of the stimulation (electric current) of 1-ms duration which, starting from 0 , was gradually increased by steps of $3 \%$ of its maximum value (i.e., $2 \mathrm{~mA}$, each of the two stimulators delivering a maximum of $1 \mathrm{~mA}$ ), and manually until a maximum CAP amplitude was obtained. Secondly, a stimulus-response curve was generated automatically by the program, from which four parameters characteristic of sensory nerve or neuromuscular excitability were estimated ("QTracP" program). These parameters included (1) the maximal CAP amplitude (CAPmax), which depended on the number of muscle and nerve fibers responding to stimulation; (2) the stimulation intensity necessary to generate a CAP with an amplitude equal to $50 \%$ of its maximum value (SI-50\%), which depended on the excitability threshold of fibers; (3) the slope of the stimulus-response curve (Slope), which depended essentially on the passive membrane properties of fibers; and (4) the time between the stimulus onset and the first peak amplitude of CAP (Latency), which depended on the CAP propagation/transmission velocity. Therefore, changes in these parameters gave information mainly on the density and functional state (activation) of voltagegated sodium $\left(\mathrm{Na}_{\mathrm{V}}\right)$ and potassium $\left(\mathrm{K}_{\mathrm{V}}\right)$ channels, as well as on the passive membrane properties of nerve fibers linked, in particular, to the presence or absence of a myelin sheath surrounding the axons.

Data are presented as means \pm standard deviations (S.D.) of at least 5 (n) different mice (6 and 5-6 animals 2 and 4 weeks after immunization, respectively). Differences between values were tested using the parametric two-tailed Student's $t$ test (either paired samples for comparison within a single population or unpaired samples for comparison between two independent populations), and the one- or two-way analysis of variance (ANOVA for comparison between the means of independent populations) or the non-parametric MannWhitney $U$ test, depending on the equality of variances

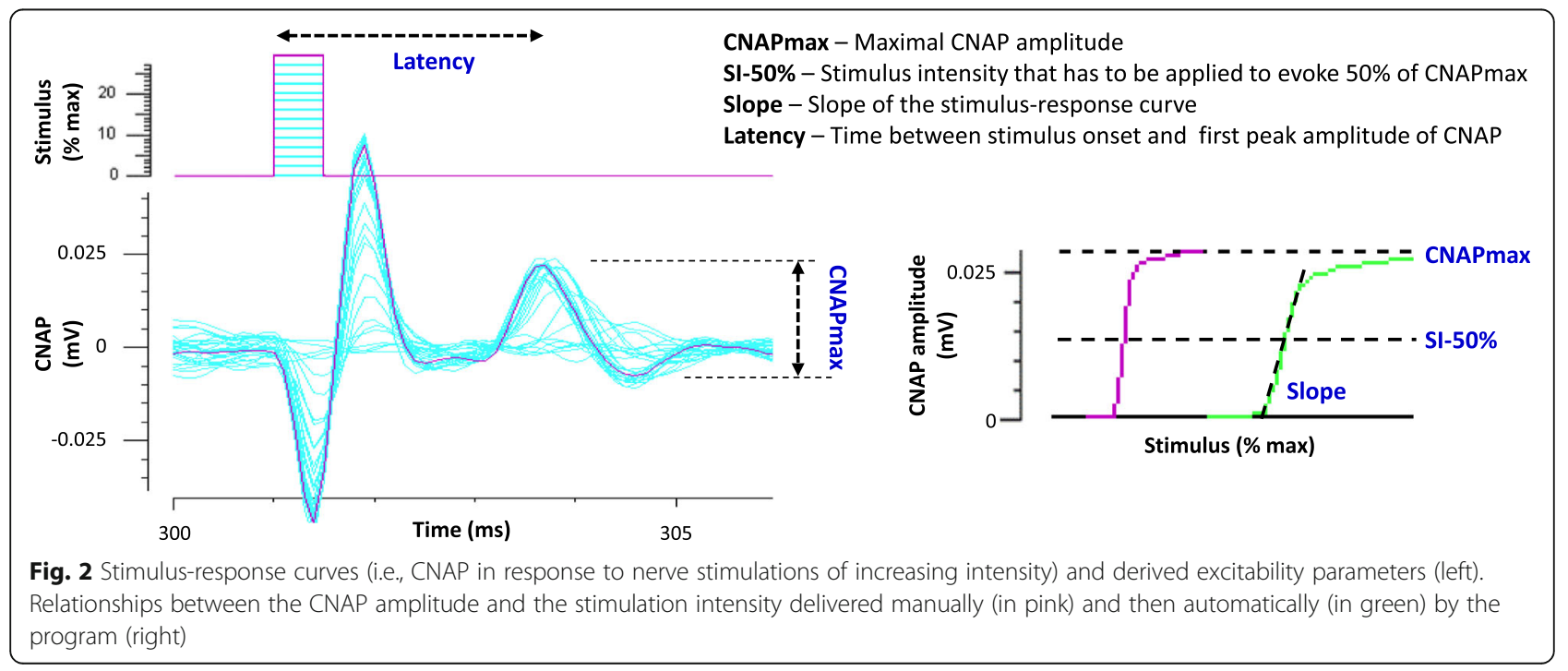


estimated using the Lilliefors' test. Differences between results are considered to be statistically significant for a $P$ value of less than or equal to 0.05 .

\section{Evaluation of myelin thickness through transmission electronic microscopy}

Under anesthesia with ketamine and xylazine $(75 \mathrm{mg} / \mathrm{kg}$ and $10 \mathrm{mg} / \mathrm{kg}$, respectively, intraperitoneal), mice were perfused with modified Karnovsky fixative solution containing $2.5 \%$ glutaraldehyde and $2 \%$ paraformaldehyde in $0.1 \mathrm{M}$ sodium phosphate buffer solution ( $\mathrm{pH}$ 7.4). The muscles of the right hind leg were dissected and the right sciatic nerve was collected. Samples were postfixed in a solution of $1 \%$ osmium tethoxide, at $4{ }^{\circ} \mathrm{C}$, followed by immersion in a $5 \%$ aqueous uranyl acetate solution at room temperature. After dehydration in alcohol, samples were immersed in propylene oxide and then included in Spur resin. Samples were sectioned (semithin sections-15 $\mu \mathrm{M}$ ) in an ultra-microtome (Reichert Ultra $\mathrm{Cut}^{\circ}$ ) and stained with $1 \%$ toluidine blue solution. Subsequently, ultra-thin sections were cut $(60 \mathrm{~nm})$, collected them on 200 mesh copper grid $\left(\mathrm{Sigma}^{\circ}\right)$, and the contrast was obtained using $4 \%$ uranyl acetate solution and $0.4 \%$ aqueous lead citrate solution [40]. The grids were examined in the Jeol 1010 transmission electron microscope (Department of Anatomy at the University of São Paulo) and quantification was performed using ImageJ software (NIH/EUA).

\section{Results}

\section{Clinical scores of EAE and control mice}

The clinical scores of MOG- and CFA-mice were determined every day after immunization, for 6 weeks, to describe the motor symptoms that occurred in the progression of EAE (Fig. 3).

As expected, the mean clinical score increased from 0.0 to more than 2.5 within about 18 days after immunization for MOG-mice while it remained null for all CFA-mice. It is worth noting that a quite large clinical score variability occurred between EAE mice.

\section{Mouse body weight and temperature}

Significant decreased body weight were observed in MOG-mice compared to CFA-animals, 2 weeks $(P=$ $0.001)$ and, although less pronounced, 4 weeks $(P=$ 0.027) after immunization (Fig. 4). However, compared

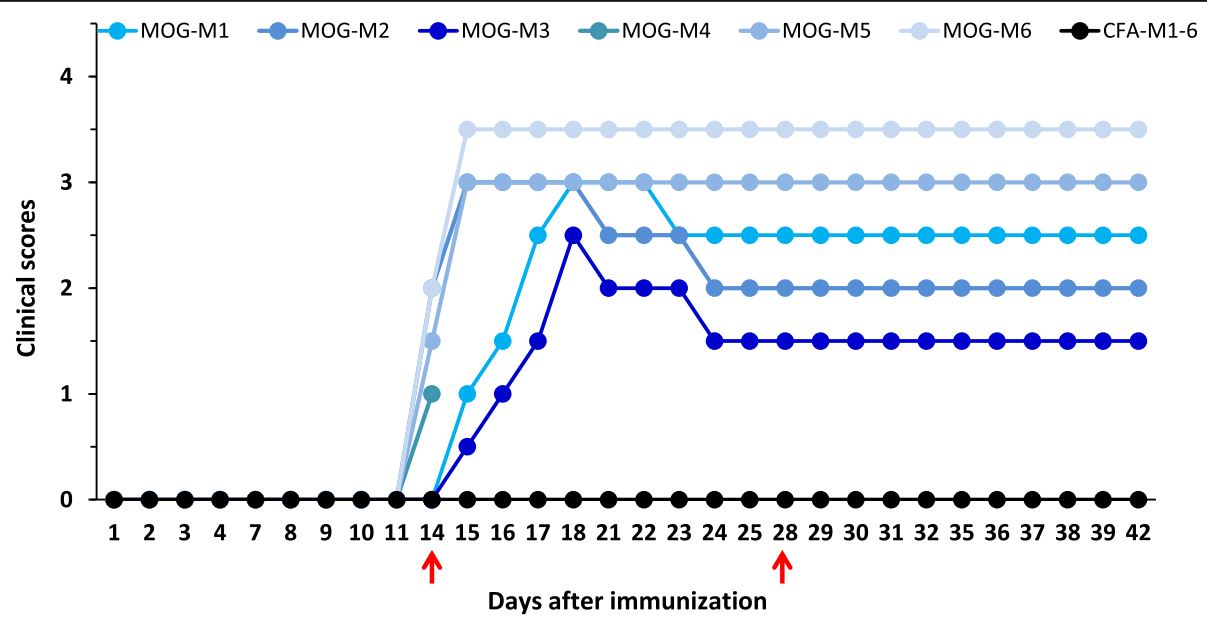

Clinical scores

$\mathbf{0 . 0}$ - No symptom

0.5 - Partial paralysis of the tail

1.0 - Total paralysis of the tail

1.5 - Dragging the hip, but fully moving the hind-limbs

2.0 - Partial paralysis of hind-limbs

2.5 - Total paralysis of one hind-limb and partial paralysis of the other

3.0 - Total paralysis of hind-limbs

3.5 - Total paralysis of hind-limbs and column arched

$\mathbf{4 . 0}$ - Total paralysis of hind-limbs and partial paralysis of fore-limbs

5.0 - Decreased responsiveness (end-point) and death

Fig. 3 Individual clinical scores of 6 EAE mice (MOG-M1 to MOG-6) and control mice (CFA-M1 to CFA-6) as a function of time after immunization at day 0 . The red arrows indicate the days of electrophysiological recordings (i.e., 2 and 4 weeks) after immunization 
to initial body weight measurements performed the day of immunization (day 0), i.e., $19.58 \pm 0.43(n=6)$, EAE mice lost weight 2 weeks after immunization $(P=0.0002)$ and then gained weight 4 weeks after immunization $(P=$ $0.435)$. On the contrary, control animals homogeneously gained weight $(P<0.013)$, compared to initial body weight measurements performed at day 0, i.e., $19.63 \pm 0.28(n=6)$.

No significant change $(P \geq 0.492)$ in body temperature was detected between EAE and control mice, whatever the number of weeks after immunization (Fig. 4).

\section{Sensory nerve excitability properties (CNAP recordings)}

As shown in Fig. 5, a significant decrease of the maximal CNAP amplitude $(P \leq 0.012)$ and of the slope of the stimulus-response curve $(P \leq 0.008)$, as well as a significant increase in the time between the stimulus onset and the first peak amplitude of CNAP $(P \leq 0.035)$, were observed in MOG-mice, compared to CFA-animals, at any given time-point. This indicates a lower propagation velocity of CNAP in EAE than in control animals.

These changes in the four parameters derived from the stimulus-response curve are exemplified in Fig. 6 by CNAP recordings obtained from individual MOG- and CFA-mice, 4 weeks after immunization.

Similarly, low propagation velocity of CNAP (increased Latency) and sensory nerve hyperexcitability (decreased SI-50\%) in EAE mice, compared to control animals, are exemplified in Fig. 7 by CNAP recordings obtained from individual MOG- and CFA-mice, 2 weeks after immunization.

\section{Motor nerve excitability properties (CMAP recordings)}

The CMAP recorded at the tail and plantar muscles of EAE mice was generally followed by a second CMAP (of reduced amplitude), as illustrated in Fig. 8, 4 weeks after immunization.

The second CMAP was detected in 50\% EAE mice (3/6 animals) 2 weeks after immunization while, 4 weeks after immunization, it was systematically observed in $100 \%$ EAE mice (5/5 animals). This second CMAP never occurred in control mice (6/6 and 6/6 animals, 2 and 4 weeks after immunization, respectively). As already stated in the "Materials and methods" section, the CMAP in response to a single stimulation consisted of a positive phase followed by a negative one (as exemplified by tail muscle recordings) or a negative phase followed by a positive one (as exemplified by plantar muscle recordings), according to the relative positions of the two detection electrodes.

Expressing the CMAP amplitude as a percentage of the first CMAP amplitude revealed a high interindividual variability in the second CMAP amplitude (Fig. 9a-b), as already observed for the EAE mouse clinical scores (see Fig. 3). Indeed, establishing the relationship between the second CMAP amplitude and the EAE mouse clinical scores revealed a good correlation $\left(r^{2} \geq\right.$ 0.677) between these two parameters (Fig. 9c). It is thus likely that the individual variability in both the presence and amplitude of the second CMAP reflected that of clinical scores.

In addition to the presence of a second CMAP in EAE mice, a significant decrease of the stimulation intensity necessary to generate a CMAP with an amplitude equal to $50 \%$ of its maximum value $(P \leq 0.038)$ was detected in MOG-mice, compared to CFA-animals, at any given time-point (Table 1, Supplementary Figures 1 and 2), as observed for the CNAP (see Fig. 5). However, the delay between the two CMAPs, measured as the time between their first peak amplitude, was constant, i.e., between 3.5

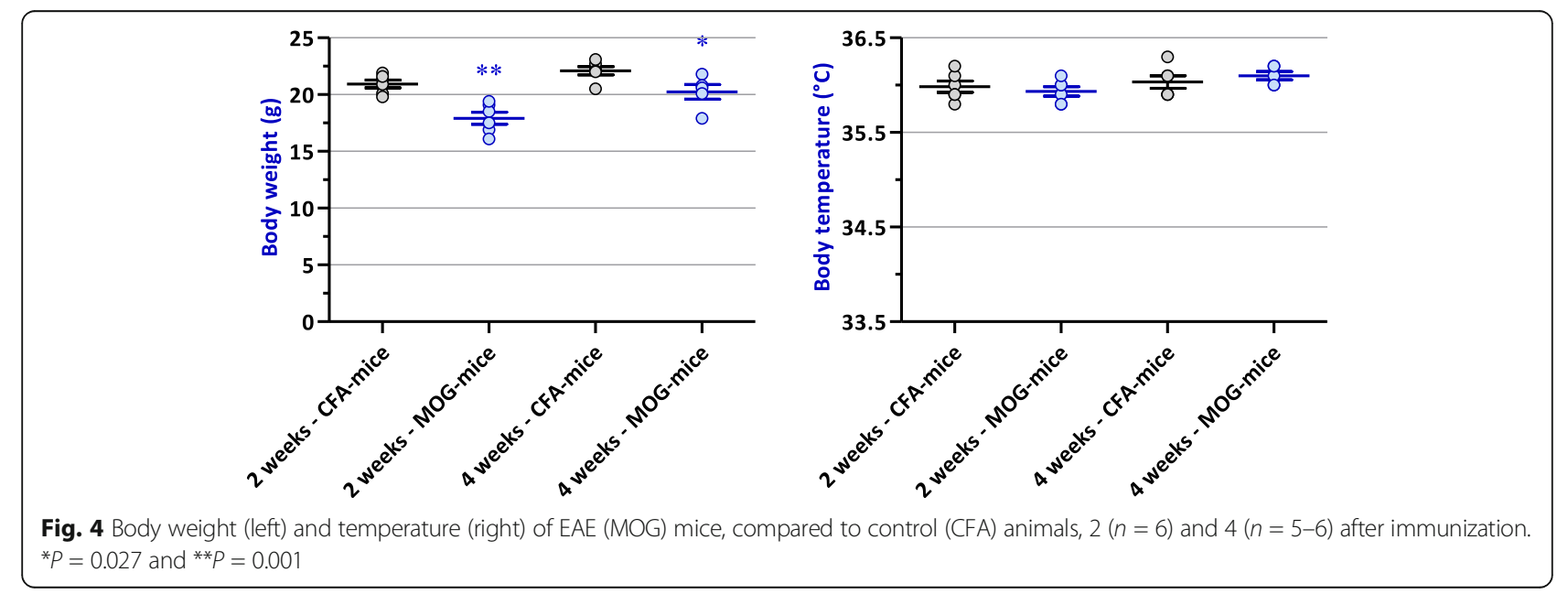



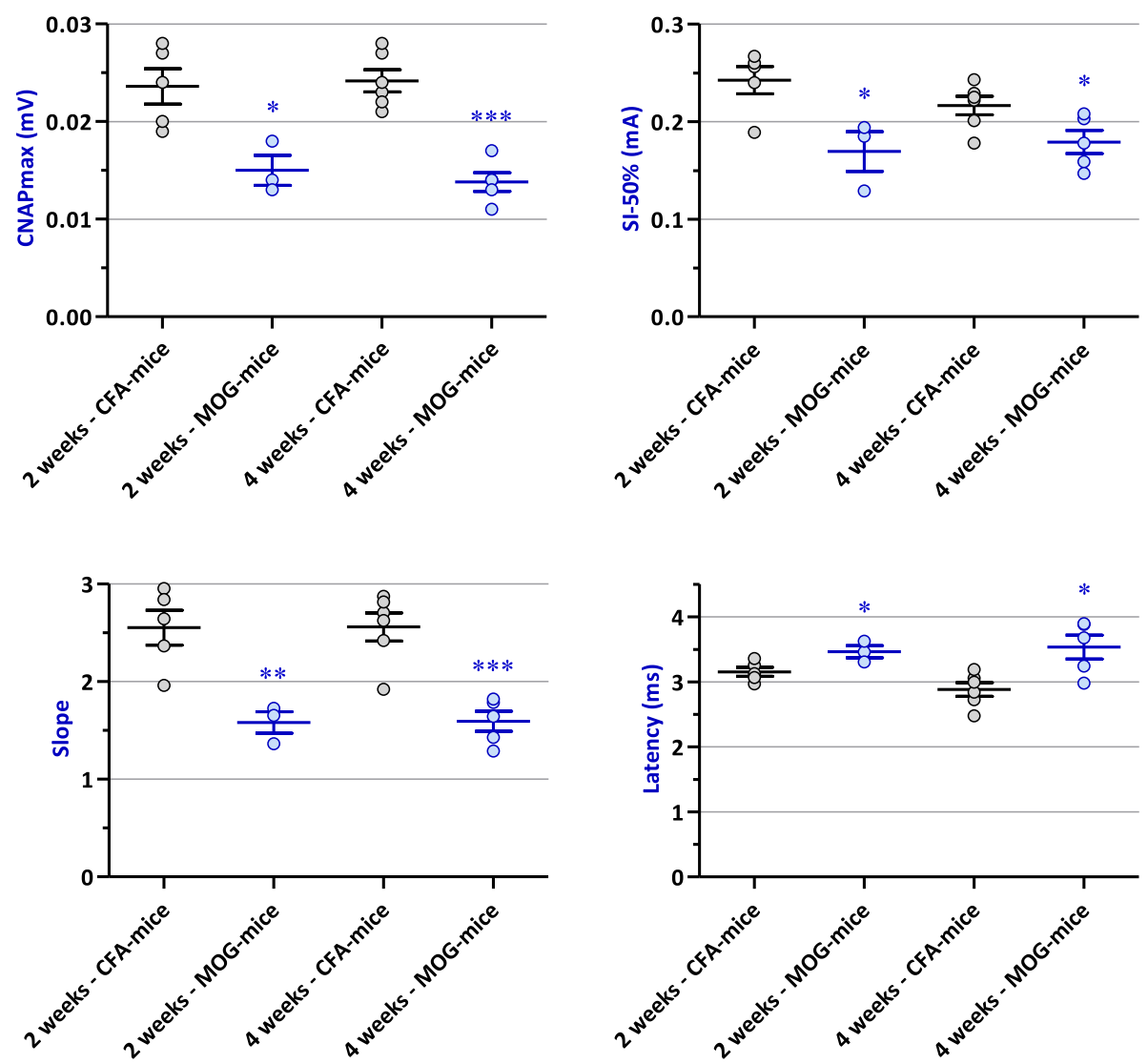

Fig. 5 Maximal CNAP amplitude (CNAPmax), stimulation intensity necessary to generate a CNAP with an amplitude equal to $50 \%$ of its maximum value (SI-50\%), slope of the stimulus-response curve (Slope), and time between the stimulus onset and the first peak amplitude of CNAP (Latency) in EAE (MOG) mice, compared to control (CFA) animals, $2(n=3-5)$ and $4(n=5-6)$ weeks after immunization. ${ }^{*} P \leq 0.035$, ${ }^{* *} P \leq 0.008$, and ${ }^{* * *} P$ $\leq 0.0005$
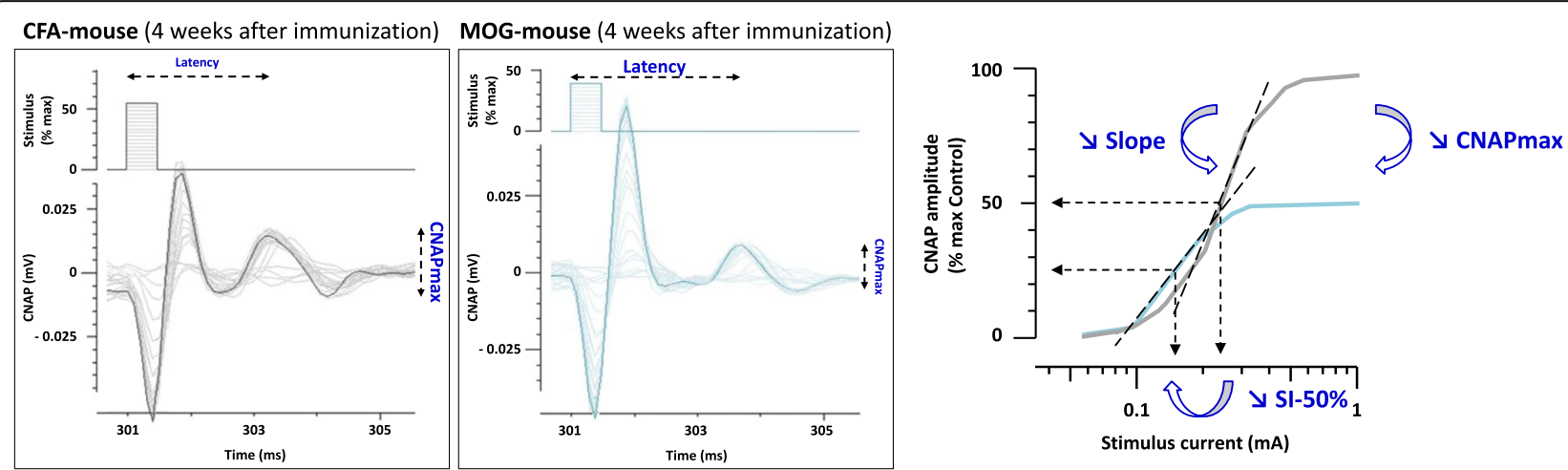

Fig. 6 Example of increased Latency and decreased CNAPmax, Slope, and SI-50\% in an EAE (MOG) mouse, compared to a control (CFA) animal, 4 weeks after immunization 

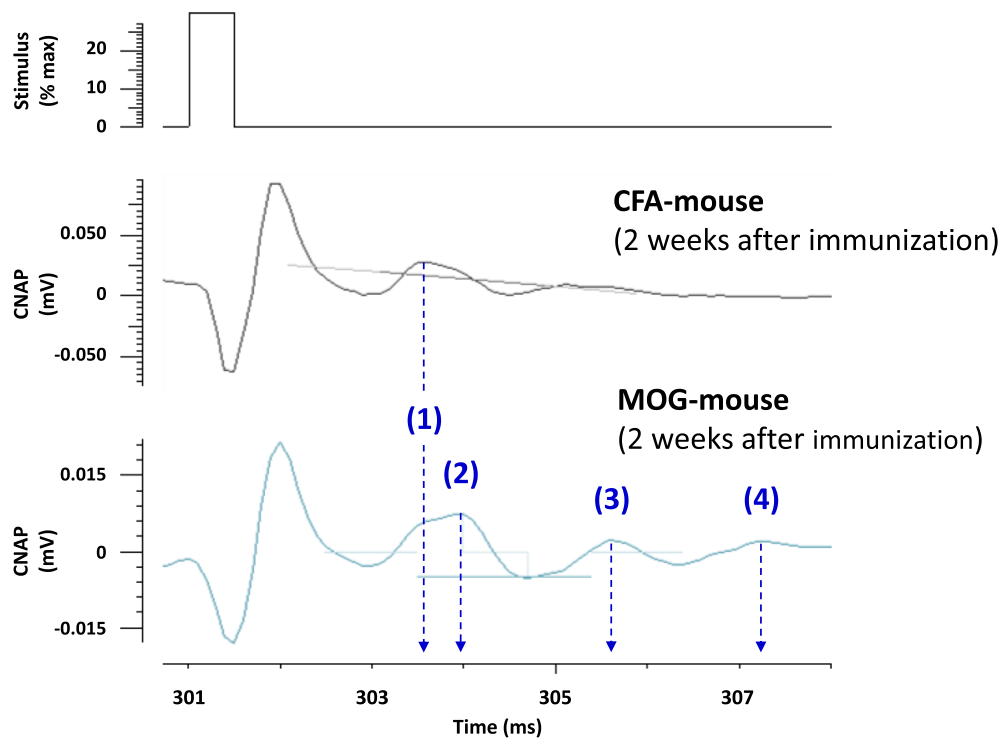

Fig. 7 Low propagation velocity of CNAP (increased Latency) and sensory nerve hyperexcitability (decreased SI-50\%) in EAE (MOG) mice, compared to control (CFA) animals, are exemplified by CNAP recordings showing (1) "control-like" (i.e., unaffected), (2) "slower", (3) "very slower", and (4) "very very slower" conducting nerve fibers in a MOG-mouse, compared to a CFA-animal, 2 weeks after immunization

and $4 \mathrm{~ms}$ (see Fig. 8), and no significant difference of the time between the stimulus onset and the first peak amplitude of the first CMAP ( $P \geq 0.292)$ was detected between EAE and control mice (Table 1, Supplementary Figures 1 and 2).

Additionally, and as already observed for the CNAP (see Fig. 5), a significant decrease of the maximal CMAP amplitude $(P \leq 0.039)$ and of the slope of the stimulusresponse curve $(P \leq 0.048)$ was observed in MOG-mice, compared to CFA-animals, at any given time-point (Table 1, Supplementary Figures 1 and 2).

\section{Myelin sheath thickness of EAE and control mice}

To verify the alterations in the myelin contend induced in the EAE model, the morphology of the distal portion of the sciatic nerve was analyzed by transmission electron microscopy on the 2nd (peak of the disease) and 4th weeks after immunization. The

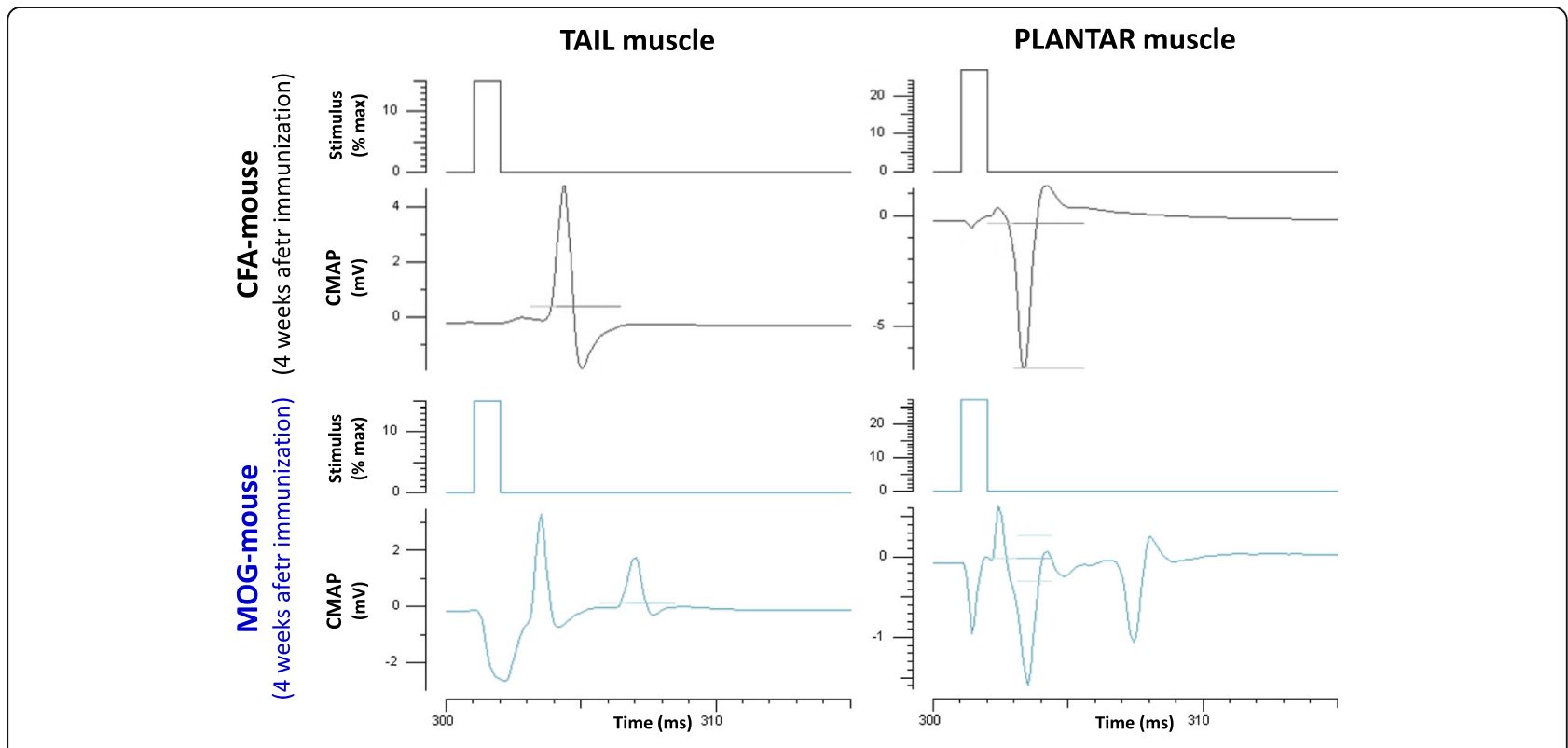

Fig. 8 Traces of CMAP recorded from the tail and plantar muscles of a control (CFA) mouse and an EAE (MOG) animal, 4 weeks after immunization 


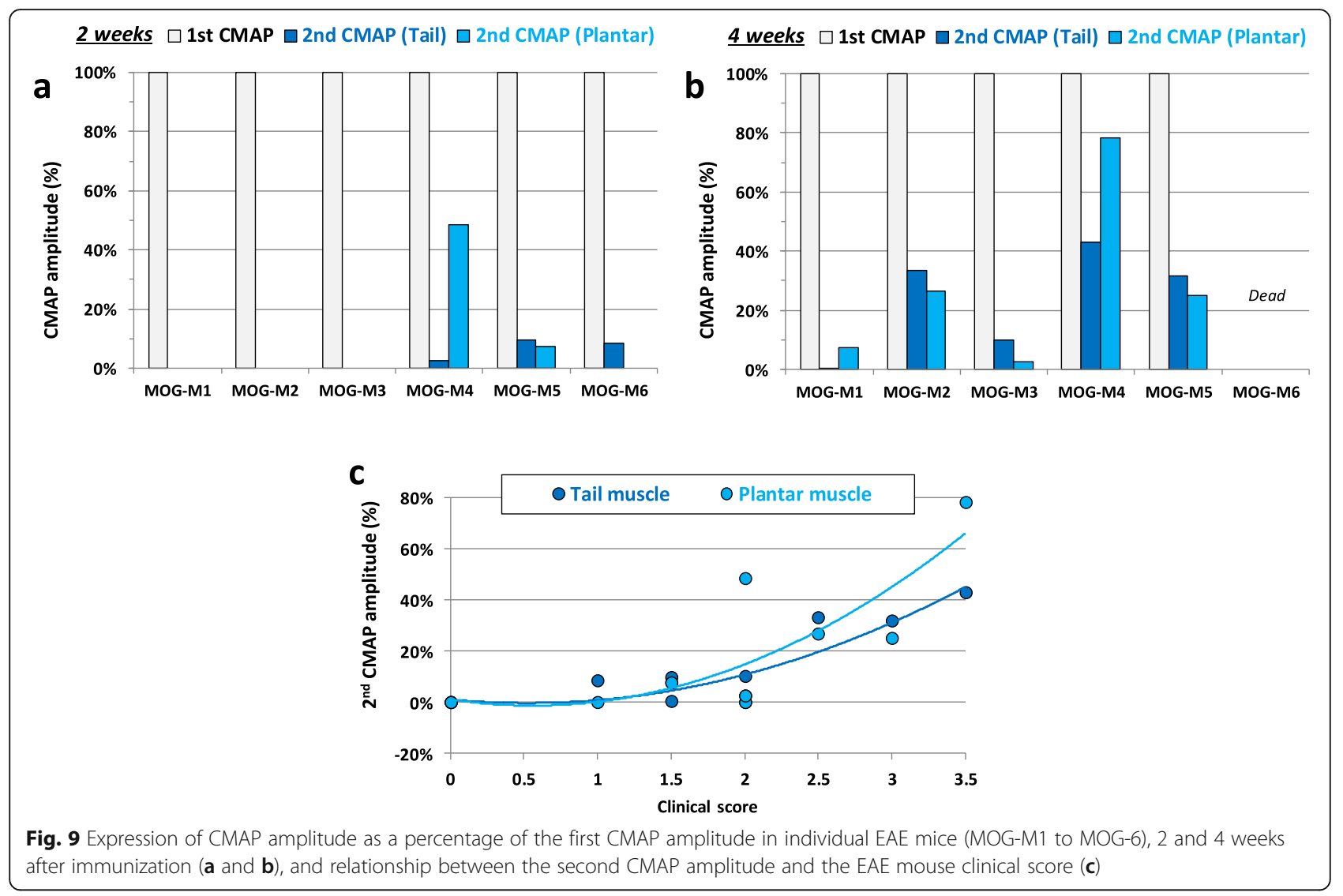

thickness of the myelin sheath was quantified by calculating the g-ratio (i.e., the axon diameter divided by the fiber diameter). The results demonstrated intact fibers, with similar distribution of myelinic fibers of small and large diameters, non-myelinic fibers, and Schwann cell nuclei in the control group. No difference in myelin sheath thickness was observed between control and EAE mice, at the peak of the disease. In contrast, a decreased sciatic nerve myelin thickness, represented by an increase in the g-ratio, was observed in the EAE group, compared to control animals, in the 4th week after immunization (Fig. 10).

Table 1 Parameters (means \pm S.D.) of the stimulus-response curve determined from tail and plantar muscles in $n$ (numbers in parentheses) EAE (MOG) mice, compared to control (CFA) animals, 2 and 4 weeks after immunization

\begin{tabular}{|c|c|c|c|c|}
\hline & \multicolumn{2}{|l|}{2 weeks } & \multicolumn{2}{|l|}{4 weeks } \\
\hline & CFA-mice (6) & MOG-mice (6) & CFA-mice (6) & MOG-mice (5) \\
\hline \multicolumn{5}{|l|}{ Tail muscle } \\
\hline CMAPmax (mV) & $6.922 \pm 0.773$ & $3.893 \pm 0.544^{*}$ & $5.992 \pm 0.469$ & $3.787 \pm 0.511^{*}$ \\
\hline SI-50\% (mA) & $0.222 \pm 0.014$ & $0.179 \pm 0.006^{*}$ & $0.224 \pm 0.015$ & $0.166 \pm 0.013^{*}$ \\
\hline Slope & $5.226 \pm 0.451$ & $3.258 \pm 0.515^{*}$ & $4.977 \pm 0.238$ & $3.982 \pm 0.112^{*}$ \\
\hline Latency (ms) & $3.854 \pm 0.067$ & $3.703 \pm 0.104$ & $3.987 \pm 0.130$ & $3.818 \pm 0.075$ \\
\hline \multicolumn{5}{|l|}{ Plantar muscle } \\
\hline CMAPmax (mV) & $6.075 \pm 0.650$ & $3.204 \pm 0.513^{* *}$ & $5.635 \pm 0.588$ & $3.011 \pm 0.522^{*}$ \\
\hline SI-50\% (mA) & $0.278 \pm 0.023$ & $0.174 \pm 0.010^{* *}$ & $0.320 \pm 0.014$ & $0.231 \pm 0.013^{* *}$ \\
\hline Slope & $6.261 \pm 0.650$ & $3.559 \pm 0.405^{*}$ & $5.756 \pm 0.337$ & $4.051 \pm 0.206^{* *}$ \\
\hline Latency (ms) & $3.044 \pm 0.201$ & $3.625 \pm 0.223$ & $3.286 \pm 0.147$ & $3.346 \pm 0.205$ \\
\hline
\end{tabular}

CMAPmax maximal CMAP amplitude, SI-50\% stimulation intensity necessary to generate a CMAP with an amplitude equal to $50 \%$ of its maximum value, Slope slope of the stimulus-response curve, Latency time between the stimulus onset and the first peak amplitude of CMAP. ${ }^{*} P \leq 0.048$ and ${ }^{* *} P \leq 0.007$ 


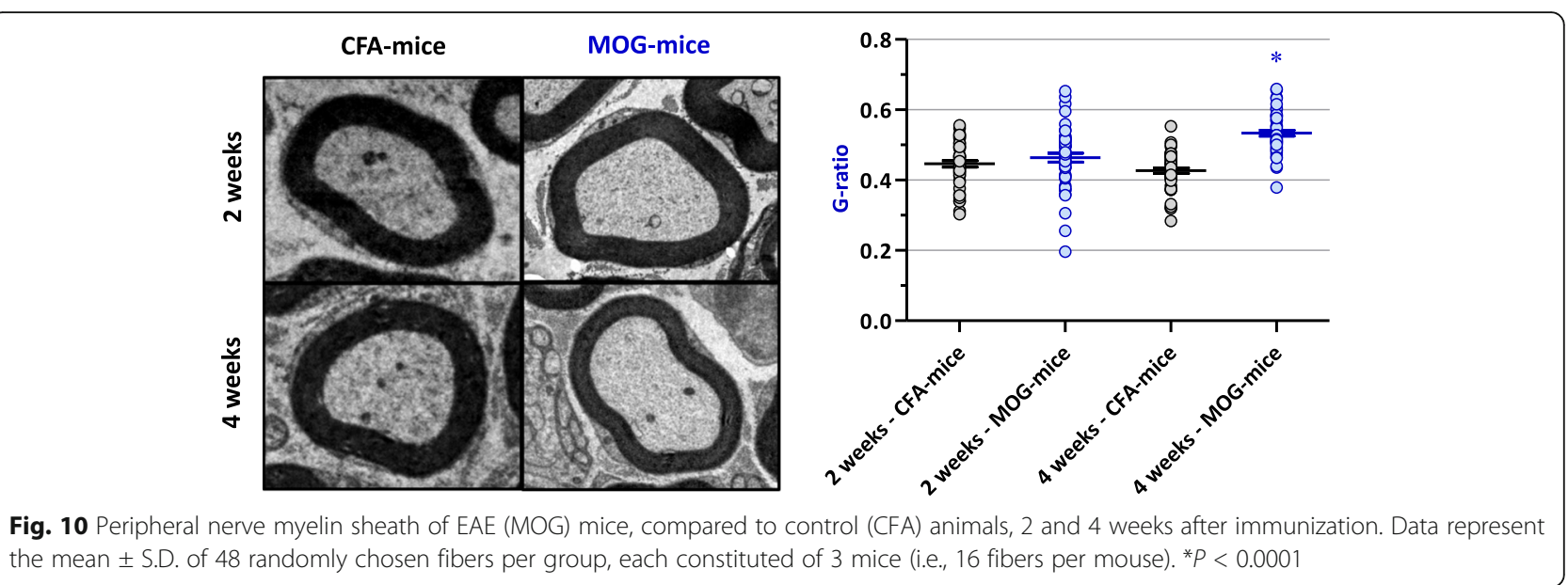

\section{Discussion}

The results of this study can be summarized as follow: (i) a large inter-individual clinical score variability between EAE mice, (ii) a difference in body weight between EAE and control mice, (iii) modifications of the peripheral sensory nerve excitability parameters, and (iv) modifications of the neuromuscular excitability parameters.

The large inter-individual variability in clinical score between EAE mice may be attributed to differences in the susceptibility to EAE, as previously observed even in genetically identical animals [41]. Despite this variability in the intensity of the clinical score among the animals, all immunized mice developed some degrees of motor impairment characteristic of the disease, while none of the control animals showed this symptom.

We observed that EAE mice first lost and then progressively gained weight while control animals homogeneously gained weight, compared to initial body weight measurements performed at day 0 . As a consequence, a difference in body weight between EAE and control mice, which is less marked as the number of weeks increased after immunization, was detected. These observations may be related to the fact that EAE mice had moving difficulties because of hind-limb paralysis and, therefore, did less exercise than control mice and that EAE animals showing a more than 2.0 clinical score were fed with highly nutritious food.

The results obtained from CNAP and CMAP recordings strongly suggest that the peripheral sensory nerve and neuromuscular excitability properties of EAE mice are markedly modified compared to those of control animals, 2 and 4 weeks after immunization. These modifications are not due to differences in body temperature since no significant change in this parameter was detected between EAE and control mice, whatever the number of weeks after immunization. They consist in a significant decrease of maximal CNAP and CMAP amplitudes, of the stimulation intensity necessary to generate a CNAP or CMAP with an amplitude equal to $50 \%$ of its maximum value, and of the slope of stimulusresponse curves at any given time-point. In addition, a significant increase in the time between the stimulus onset and the first peak amplitude of CNAP was observed in MOG-mice compared to CFA-animals, at any given time-point, indicating a lower propagation velocity of the electrical transmission of the action potential in EAE than in control animals. In contrast, no significant difference of the time between the stimulus onset and the first peak amplitude of the first CMAP was detected between EAE and control mice. This strongly suggests that the chemical transmission of the action potential at the neuromuscular junction is not delayed. These electrophysiological abnormalities are similar to those previously reported in the ulnar and sural sensory nerves of some MS patients diagnosed according to the criteria of Poser Scale [28] and in superficial radial sensory axons of a few patients with relapsing-remitting MS [29]. They are also in accordance with the high frequency of electrophysiological abnormalities previously reported in the tibial motor nerve of a selected group of MS patients [28].

The significant decrease of the stimulation intensity necessary to generate a CNAP or a CMAP with an amplitude equal to $50 \%$ of its maximum value detected in MOG-mice, compared to CFA-animals, indicates sensory and motor nerve hyperexcitability in EAE mice compared to control animals. In agreement, membrane hyperexcitability of sensory neurons of dorsal root ganglia isolated from $\mathrm{MOG}_{35-55}$-induced EAE mice was previously reported [23]. Besides, the presence of a second CMAP in EAE mice may also express membrane hyperexcitability. However, the fact that the delay between the two CMAPs, measured as the time between their first peak amplitude, was constant strongly suggests that this second CMAP may also result from the activity of slow conducting motor nerve fibers, as expected if a 
demyelinating process occurs in the peripheral nervous system of EAE mice. Under these conditions, the first CMAP would be due to unaffected axons, whereas the second one would correspond to partially demyelinated axons. This is in agreement with the absence of detection of time difference between the stimulus onset and the first peak amplitude of the first CMAP in EAE mice, compared to control animals. Moreover, the recordings of multiple (at least 4) CNAP peaks may reflect not only the decrease of both the propagation velocity and the SI$50 \%$ parameter of CNAP but also various populations of sensory nerve fibers having different CNAP conduction speeds in EAE mice. This is expected if a demyelinating process occurred in the peripheral nervous system of EAE mice.

To support the occurrence of a peripheral demyelinating process, we investigated the alterations of sciatic nerve myelin contend by transmission electron microscopy, a methodology previously used as a parameter of peripheral myelin analysis for evaluation of neuroprotective therapies evaluation [42]. Although the widely expression of myelin peptides as MBP and MOG in the CNS is remarkable [43-46], these proteins are also expressed in the PNS [47-50], the thymus, and the spleen [51, 52]. These proteins can therefore be a target of autoantibodies attack, contributing to demyelination at peripheral level and, as a consequence, to peripheral sensory and motor alterations.

\section{Conclusion}

In conclusion, the main modifications of the peripheral sensory nerve and neuromuscular excitability are (i) a membrane hyperexcitability likely related to membrane depolarization and (ii) the presence of slow conducting sensory and motor nerve fibers due to a demyelinating process occurring in the PNS of EAE mice. These modifications are of great interest since the loss of immunological self-tolerance to MOG in EAE animal model or in patients with MS is generally attributed to the restricted expression of this antigen in the immunologically privileged environment of the CNS.

\section{Supplementary information}

Supplementary information accompanies this paper at https://doi.org/10. 1186/s12974-020-01936-9.

Additional file 1: Supplementary Figure 1. Parameters of stimulusresponse curves determined from tail muscle recordings in EAE (MOG) mice compared to control (CFA) animals. Supplementary Figure 2. $\mathrm{Pa}$ rameters of stimulus-response curves determined from plantar muscle recordings in EAE (MOG) mice compared to control (CFA) animals.

\section{Abbreviations}

ANOVA: Analysis of variance; ARRIVE: Animal Research: Reporting of In Vivo Experiments; CAP: Compound action potential; CAPmax: Maximal CAP amplitude; CFA: Complete Freund's adjuvant; CMAP: Compound muscle action potential; CNAP: Compound nerve action potential; CNS: Central nervous system; EAE: Experimental autoimmune encephalomyelitis; IFA: Incomplete Freund's adjuvant; $K_{V}$ channel: Voltage-gated potassium channels; Latency: Time between the stimulus onset and the first peak amplitude of CAP; MBP: Myelin basic protein; MOG: Myelin oligodendrocyte glycoprotein; MS: Multiple sclerosis; Nav channel: Voltage-gated sodium channel; PNS: Peripheral nervous system; SI-50\%: Stimulation intensity necessary to generate a CAP with an amplitude equal to $50 \%$ of its maximum value; Slope: Slope of the stimulus-response curve; Th1: T-helper type 1 cell; Th17: T-helper type 17 cell

\section{Acknowledgements}

Not applicable.

\section{Authors' contributions}

GP, FB, GP, BK, DS, and EB conceived and designed the experiments; NBT, $A C G$, and $E B$ performed and analysed the experiments; $G P$ and $E B$ wrote and prepared the original draft; GP, ACG, and EB wrote and prepared the revised draft; $G P, F B, G P, B K, D S$, and $E B$ reviewed and edited the paper. GP, FB, BK, and DS acquired the funding. All authors read and approved the final version of the manuscript to be published.

\section{Funding}

This research was financed by funds from the French Alternative Energies and Atomic Energy Commission (CEA, Gif sur Yvette, France), from the São Paulo Research Foundation (FAPESP, Brazil, grant number 2011/17974-2), from FAPESP_Center of Toxins, Immune Response and Cell Signaling (CeTICS, grant number 2013/07467-1), and from the Coordenação de Aperfeiçoamento de Pessoal de Nível Superior-Brasil (CAPES, Finance Code 001). Research collaboration was also supported by the IASP Developing Countries Collaborative Research Grant.

\section{Availability of data and materials}

All datasets [GENERATED/ANALYZED] for this study are included in the manuscript and the supplementary files.

\section{Ethics approval and consent to participate}

Animal experiments, reported in line with the ARRIVE (Animal Research: Reporting of In Vivo Experiments) guidelines developed in consultation with the scientific community as part of an NC3Rs initiative to improve standards of reporting the results of animal experiments, maximizing information published and minimizing unnecessary studies, were carried out on mice purchased from Janvier Elevage (Le Genest-Saint-Isle, France). The animals were hosted at the CEA animal facility and were treated in strict adherence with the European Community guidelines for laboratory animal handling and to the guidelines established by the French Council on animal care "Guide for the Care and Use of Laboratory Animals" (EEC86/609 Council Directive-Decree 2001-131). All animal experimental procedures were approved by the Animal Ethics Committee of the CEA, by the French General Directorate for Research and Innovation (project APAFIS\#5973-

$2016070515456532 v 6$ authorized to FB and project APAFIS\#2671-

2015110915123958v4 authorized to EB) and by the Butantan Institute (CEUAIB protocol number 7334170718 authorized to GP).

Consent for publication

Not applicable.

\section{Competing interests}

The authors declare that they have no competing interests.

\section{Author details}

${ }^{1}$ Université Paris-Saclay, CEA, Département Médicaments et Technologies pour la Santé (DMTS), Service d'Ingénierie Moléculaire pour la Santé (SIMoS), ERL CNRS 9004, Gif-sur-Yvette, France. 'Laboratory of Pain and Signaling, Butantan Institute, São Paulo, Brazil. ${ }^{3}$ Université Paris-Saclay, CEA, NeuroSpin, Gif-sur-Yvette, France. ${ }^{4}$ Université Paris-Saclay, CEA, Inserm, BioMaps, Orsay, France. 
Received: 5 May 2020 Accepted: 20 August 2020

\section{Published online: 07 September 2020}

\section{References}

1. Ontaneda D, Thompson AJ, Fox RJ, Cohen JA. Progressive multiple sclerosis: prospects for disease therapy, repair, and restoration of function. Lancet. 2017;389:1357-66. https://doi.org/10.1016/S0140-6736(16)31320-4

2. Brownlee WJ, Hardy TA, Fazekas F, Miller DH. Diagnosis of multiple sclerosis: progress and challenges. Lancet. 2017;389:1336-46. https://doi.org/10.1016/ S0140-6736(16)30959-X.

3. Sloane E, Ledeboer A, Seibert W, Coats B, van Strien M, Maier SF, et al. Antiinflammatory cytokine gene therapy decreases sensory and motor dysfunction in experimental multiple sclerosis: MOG-EAE behavioral and anatomical symptom treatment with cytokine gene therapy. Brain Behav Immun. 2009;23:92-100. https://doi.org/10.1016/j.bbi.2008.09.004.

4. Miller AE, Rhoades RW. Treatment of relapsing-remitting multiple sclerosis: current approaches and unmet needs. Curr Opin Neurol. 2012;25(Suppl):S410. https://doi.org/10.1097/01.wco.0000413319.87092.19.

5. Peine K, Guerau-de-Arellano M, Lee P, Kanthamneni N, Severin M, Probst $\mathrm{GD}$, et al. Treatment of experimental autoimmune encephalomyelitis by codelivery of disease associated peptide and dexamethasone in acetalated dextran microparticles. Mol Pharm. 2014;11:828-35. https://doi.org/10.1021/ mp4005172.

6. Kolahdouzan M, Futhey NC, Kieran NW, Healy LM. Novel molecular leads for the prevention of damage and the promotion of repair in neuroimmunological disease. Front Immunol. 2019;10:1657. https://doi.org/ 10.3389/fimmu.2019.01657.

7. Van Kaer L, Postoak JL, Wang C, Yang G, Wu L. Innate, innate-like and adaptive lymphocytes in the pathogenesis of MS and EAE. Cell Mol Immunol. 2019;16:531-9. https://doi.org/10.1038/s41423-019-0221-5.

8. Martin R, Sospedra M, Rosito M, Engelhardt B. Current multiple sclerosis treatments have improved our understanding of MS autoimmune pathogenesis. Eur J Immunol. 2016;46:2078-90. https://doi.org/10.1002/eji. 201646485.

9. Yadav SK, Mindur JE, Ito K, Dhib-Jalbut S. Advances in the immunopathogenesis of multiple sclerosis. Curr Opin Neurol. 2015;28:20619. https://doi.org/10.1097/WCO.0000000000000205.

10. Yu XL, Yan CZ, Ji KQ, Lin PF, Xu XB, Dai TJ, Li W, Zhao YY. Clinical, neuroimaging, and pathological analyses of 13 Chinese Leigh syndrome patients with mitochondrial DNA mutations. Chin Med J. (2018) 131:27052712. doi: https://doi.org/10.4103/0366-6999.245265.

11. Huang WJ, Chen WW, Zhang X. Multiple sclerosis: pathology, diagnosis and treatments. Exp Ther Med. 2017;13:3163-6. https:/doi.org/10.3892/etm.2017.4410.

12. Abdelhak A, Hottenrott T, Morenas-Rodríguez E, Suárez-Calvet M, Zettl UK, Haass C, et al. Glial activation markers in CSF and serum from patients with primary progressive multiple sclerosis: potential of serum GFAP as disease severity marker? Front Neurol. 2019;10:280. https://doi.org/10.3389/fneur. 2019.00280.

13. Storelli L, Rocca MA, Pagani E, Van Hecke W, Horsfield MA, De Stefano N, Rovira A, Sastre-Garriga J, Palace J, Sima D, Smeets D, Filippi M. Measurement of whole-brain and gray matter atrophy in multiple sclerosis: assessment with MR imaging. Radiology (2018) 288:554-564. doi: org/ https://doi.org/10.1148/radiol.2018172468.

14. Calabrese M, Magliozzi R, Ciccarelli O, Geurts JJG, Reynolds R, Martin R. Exploring the origins of grey matter damage in multiple sclerosis. Nat Rev Neurosci. 2015;16:147-58. https://doi.org/10.1038/nrn3900.

15. Haider L, Simeonidou C, Steinberger G, Hametner S, Grigoriadis N, Deretzi G, et al. Multiple sclerosis deep grey matter: the relation between demyelination, neurodegeneration, inflammation and iron. J Neurol Neurosurg Psychiatry. 2014;85:1386-95. https://doi.org/10.1136/jnnp-2014-307712.

16. Eshaghi A, Marinescu RV, Young AL, Firth NC, Prados F, Cardoso J, Tur C, De Angelis F, Cawley N, Brownlee WJ, De Stefano N, Stromillo L, Battaglini M, Ruggieri S, Gasperini C, Filippi M, Rocca MA, Rovira A, Sastre-Garriga J, Geurts JJG, Vrenken H, Wottschel V, Leurs CE, Uitdehaag B, Pirpamer L, Enzinger C, Ourselin S, Wheeler-Kingshott CAG, Chard D, Thompson AJ, Barkhof F, Alexander DC, Ciccarelli O. Progression of regional grey matter atrophy in multiple sclerosis. Brain (2018) 141:1665-1677. doi: org/https:// doi.org/10.1093/brain/awy088.

17. Lamoureux G, Jolicoeur R, Giard N, St-Hilaire M, Duplantis F. Cerebrospinal fluid proteins in multiple sclerosis. Neurology. 1975;25:537-46. https://doi. org/10.1212/wnl.25.6.537.
18. Johnson KP, Arrigo SC, Nelson BJ, Ginsberg A. Agarose electrophoresis of cerebrospinal fluid in multiple sclerosis. A simplified method for demonstrating cerebrospinal fluid oligoclonal immunoglobulin bands. Neurology. 1977;27:273-7. https://doi.org/10.1212/wnl.27.3.273.

19. Sospedra M, Martin R. Immunology of multiple sclerosis. Annu Rev Immunol. 2005;23:683-747. https://doi.org/10.1146/annurev.immunol.23. 021704.115707.

20. Wekerle H. B cells in multiple sclerosis. Autoimmunity. 2017;50:57-60. https://doi.org/10.1080/08916934.2017.1281914.

21. Li R, Patterson KR, Bar-Or A. Reassessing B cell contributions in multiple sclerosis. Nat Immunol. 2018;19:696-707. https://doi.org/10.1038/s41590018-0135-X.

22. Pender MP, Tabi Z, Nguyen KB, McCombe PA. The proximal peripheral nervous system is a major site of demyelination in experimental autoimmune encephalomyelitis induced in the Lewis rat by a myelin basic protein-specific T cell clone. Acta Neuropathol. 1995;89:527-31. https://doi. org/10.1007/BF00571507.

23. Yousuf MS, Noh MC, Friedman TN, Zubkow K, Johnson JC, Tenorio G, et al. Sensory neurons of the dorsal root ganglia become hyperexcitable in a Tcell-mediated MOG-EAE model of multiple sclerosis. eNeuro. 2019;6(2). https://doi.org/10.1523/ENEURO.0024-19.2019.

24. Frezel N, Sohet F, Daneman R, Basbaum Al, Braz JM. Peripheral and central neuronal ATF3 precedes CD4+ T-cell infiltration in EAE. Exp Neurol. 2016; 283(Pt A):224-34. https://doi.org/10.1016/j.expneurol.2016.06.019.

25. Wang IC, Chung CY, Liao F, Chen CC, Lee CH. Peripheral sensory neuron injury contributes to neuropathic pain in experimental autoimmune encephalomyelitis. Sci Rep. 2017;7:42304. https://doi.org/10.1038/srep42304.

26. Di Trapani G, Carnevale A, Cioffi RP, Massaro AR, Profice P. Multiple sclerosis associated with peripheral demyelinating neuropathy. Clin Neuropathol. 1996;15:135-8.

27. Pirko I, Kuntz NL, Patterson M, Keegan BM, Weinshenker BG, Rodriguez M. Contrasting effects of IFNbeta and IVIG in children with central and peripheral demyelination. Neurology. 2003;60:1697-9. https://doi.org/10. 1212/01.wnl.0000064163.94122.eb.

28. Anlar O, Tombul T, Kisli M. Peripheral sensory and motor abnormalities in patients with multiple sclerosis. Electromyogr Clin Neurophysiol. 2003;43: 349-51.

29. Misawa S, Kuwabara S, Mori M, Hayakawa S, Sawai S, Hattori T. Peripheral nerve demyelination in multiple sclerosis. Clin Neurophysiol. 2008;119:182933. https://doi.org/10.1016/j.clinph.2008.04.010.

30. Basso AS, Frenkel D, Quintana FJ, Costa-Pinto FA, Petrovic-Stojkovic S, Puckett $L$, et al. Reversal of axonal loss and disability in a mouse model of progressive multiple sclerosis. J Clin Invest. 2008;118:1532-43. https://doi. org/10.1172/JCl33464.

31. Olechowski CJ, Parmar A, Miller B, Stephan J, Tenorio G, Tran K, et al. A diminished response to formalin stimulation reveals a role for the glutamate transporters in the altered pain sensitivity of mice with experimental autoimmune encephalomyelitis (EAE). Pain. 2010;149:565-72. https://doi.org/ 10.1016/j.pain.2010.03.037.

32. Warwick RA, Ledgerwood CJ, Brenner T, Hanani M. Satellite glial cells in dorsal root ganglia are activated in experimental autoimmune encephalomyelitis. Neurosci Lett. 2014;569:59-62. https://doi.org/10.1016/j. neulet.2014.03.033.

33. Kilkenny C, Browne WJ, Cuthill IC, Emerson M, Altman DG. Improving bioscience research reporting: the ARRIVE guidelines for reporting animal research. PLoS Biol. 2010;8(6):e1000412. https://doi.org/10.1371/journal.pbio. 1000412.

34. Schulz KF, Altman DG, Moher D, the CONSORT Group. CONSORT 2010 statement: updated guidelines for reporting parallel group randomised trials. BMJ (2010) 340:c332. doi: https://doi.org/https://doi.org/10.1136/ bmj.c332.

35. Eikelenboom MJ, Killestein J, Kragt JJ, Uitdehaag BMJ, Polman GH. Gender differences in multiple sclerosis: cytokines and vitamin D. J Neurol Sci. (2009) 286: 40-42. doi.org/https://doi.org/10.1016/j.jns.2009.06.025.

36. Tintoré $M$, Arrambide $G$. Early onset multiple sclerosis: the role of gender. J Neurol Sci. (2009) 286: 31-34. doi.org/https://doi.org/10.1016/j.jns.2009.07.016.

37. Wallin MT, Culpepper WJ, Campbell JD, Nelson LM, Langer-Gould A, Marrie RA, et al. The prevalence of MS in the United States: a population-based estimate using health claims data. Neurology. 2019;92(10):e1029-40. https:// doi.org/10.1212/WNL.0000000000007035 Erratum in: Neurology (2019) 93(15): 688. 
38. Legroux L, Pittet CL, Beauseigle D, Deblois G, Prat A, Arbour N. An optimized method to process mouse CNS to simultaneously analyze neural cells and leukocytes by flow cytometry. J Neurosci Methods. 2015;247:2331. https://doi.org/10.1016/j.jneumeth.2015.03.021.

39. Legroux L, Moratalla AC, Laurent C, Deblois G, Verstraeten SL, Arbour N. NKG2D and its ligand MULT1 contribute to disease progression in a mouse model of multiple sclerosis. Front Immunol. 2019;10:154. https://doi.org/10. 3389/fimmu.2019.00154.

40. Watanabe I, Yamada E. The fine structure of lamellated nerve endings found in the rat gingiva. Arch Histol Jpn. 1983;46(2):173-82. https://doi.org/10. 1679/aohc.46.173.

41. Constantinescu CS, Faroogi N, O'Brien K, Gran B. Experimental autoimmune encephalomyelitis (EAE) as a model for multiple sclerosis (MS). $\mathrm{Br} J$ Pharmacol. 2011;164:1079-106. https://doi.org/10.1111/j.1476-5381.2011. 01302.x.

42. da Silva JT, Santos FM, Giardini AC, Martins Dde O, de Oliveira ME, Ciena AP, et al. Neural mobilization promotes nerve regeneration by nerve growth factor and myelin protein zero increased after sciatic nerve injury. Growth Factors. 2015;33(1):8-13. https://doi.org/10.3109/08977194.2014.953630.

43. Solly SK, Thomas JL, Monge M, Demerens C, Lubetzki C, Gardinier MV, et al. Myelin/oligodendrocyte glycoprotein (MOG) expression is associated with myelin deposition. Glia. 1996;18(1):39-48. https://doi.org/10.1002/(SICI)10981136(199609)18:1<39::AID-GLIA4>3.0.CO;2-Z.

44. Keirstead HS, Blakemore WF. The role of oligodendrocytes and oligodendrocyte progenitors in CNS remyelination. Adv Exp Med Biol. 1999; 468:183-97. https://doi.org/10.1007/978-1-4615-4685-6_15.

45. Li G, Crang AJ, Rundle JL, Blakemore WF. Oligodendrocyte progenitor cells in the adult rat CNS express myelin oligodendrocyte glycoprotein (MOG). Brain Pathol. 2002;12(4):463-71. https://doi.org/10.1111/j.1750-3639.2002. tb00463.x.

46. El Khoury D. Study of myelin gene expression in the central nervous system using real-time PCR. Methods Mol Biol. 2019;2011:659-70. https://doi.org/10. 1007/978-1-4939-9554-7_38.

47. Itoyama Y, Webster HD, Richardson EP Jr, Trapp BD. Schwann cell remyelination of demyelinated axons in spinal cord multiple sclerosis lesions. Ann Neurol. 1983;14(3):339-46. https://doi.org/10.1002/ana. 410140313.

48. Puckett C, Hudson L, Ono K, Friedrich V, Benecke J, Dubois-Dalcq M, et al. Myelin-specific proteolipid protein is expressed in myelinating Schwann cells but is not incorporated into myelin sheaths. J Neurosci Res. 1987;18(4): 511-8. https://doi.org/10.1002/jnr.490180402

49. Griffiths IR, Mitchell LS, McPhilemy K, Morrison S, Kyriakides E, Barrie JA. Expression of myelin protein genes in Schwann cells. J Neurocytol. 1989; 18(3):345-52. https://doi.org/10.1007/BF01190837.

50. Pagany M, Jagodic M, Schubart A, Pham-Dinh D, Bachelin C, Baron van Evercooren A, et al. Myelin oligodendrocyte glycoprotein is expressed in the peripheral nervous system of rodents and primates. Neurosci Lett. 2003;350: 165-8. https://doi.org/10.1016/50304-3940(03)00899-1.

51. Anderson AC, Nicholson LB, Legge KL, Turchin V, Zaghouani H, Kuchroo VK. High frequency of autoreactive myelin proteolipid protein-specific $T$ cells in the periphery of naive mice: mechanisms of selection of the self-reactive repertoire. J Exp Med. 2000;191(5):761-70. https://doi.org/10.1084/jem.191.5.761.

52. Delarasse C, Daubas P, Mars LT, Vizler C, Litzenburger T, Iglesias A, et al. Myelin/oligodendrocyte glycoprotein-deficient (MOG-deficient) mice reveal lack of immune tolerance to MOG in wild-type mice. J Clin Invest. 2003; 112(4):544-53. https://doi.org/10.1172/JCl15861.

\section{Publisher's Note}

Springer Nature remains neutral with regard to jurisdictional claims in published maps and institutional affiliations.

Ready to submit your research? Choose BMC and benefit from:

- fast, convenient online submission

- thorough peer review by experienced researchers in your field

- rapid publication on acceptance

- support for research data, including large and complex data types

- gold Open Access which fosters wider collaboration and increased citations

- maximum visibility for your research: over $100 \mathrm{M}$ website views per year

At BMC, research is always in progress.

Learn more biomedcentral.com/submissions 